\title{
Organic Chemistry and Immunochemical Strategies in the Design of Potent Carbohydrate-based Vaccines
}

\author{
René Roy* and Tze Chieh Shiao
}

\begin{abstract}
A brief overview of carbohydrate antigens processing and uptakes involved in the adaptive immune system is highlighted. To counter balance the poor immunogenicity and T-cell independent characteristics of carbohydrate antigens, chemists have developed original hybrid molecules aimed at targeting specific competent immune cell receptors. Amongst several potential vaccine candidates dedicated against diseases, this short report will focused on those most advance and state of the art organic chemistry involved therein. One case has led to the first example of a commercial vaccine entirely prepared from a synthetic carbohydrate antigen against infections caused by the Gram-negative bacteria Haemophilus influenza type b responsible for pneumonia and acute bacterial meningitis in infants. Other commendable examples will illustrate the immunochemical strategies engaged in the development of anticancer carbohydrate-based vaccines.
\end{abstract}

Keywords: Bacteria $\cdot$ Cancer $\cdot$ Carbohydrate $\cdot$ Polysaccharides $\cdot$ Vaccines

\section{Introduction}

Although carbohydrate antigens have long been recognized as being poorly immunogenic and therefore were improper inducers of long-term protective immunity, several chemical strategies have been recently implemented to overcome their natural immunochemical incompetence. ${ }^{[1-8]}$ Carbohydrates on their own, as opposed to proteins and peptides, are thus known to be T-cell independent antigens. The consequences of this is that carbohydrates are not equipped to trigger the participation of T-helper cells and hence, could not induce immune cell proliferation, antibody class switch and affinity/specificity maturation. The major successful advances initially encountered with carbohydrate-based vaccines have been supported by the discovery that, when properly conjugated to protein carriers, serving as T-cell dependent epitopes, bacterial capsular polysaccharides became capable of acquiring the requisite immunochemical ability. A brief overview of the three known carbohydrate antigen uptake mechanisms by antigen presenting cells (APCs) represented by the families of dendritic cells, B-cells, and macrophages is presented herein (Fig. 1). ${ }^{[5,9]}$ Thus, as stated above, the most studied and successful glycoconjugate vaccines were those made of bacterial capsular polysaccharides that were covalently bound to strongly immunogenic protein carriers such as keyhole limpet hemocyanin (KLH), tetanus toxoid (TT) and

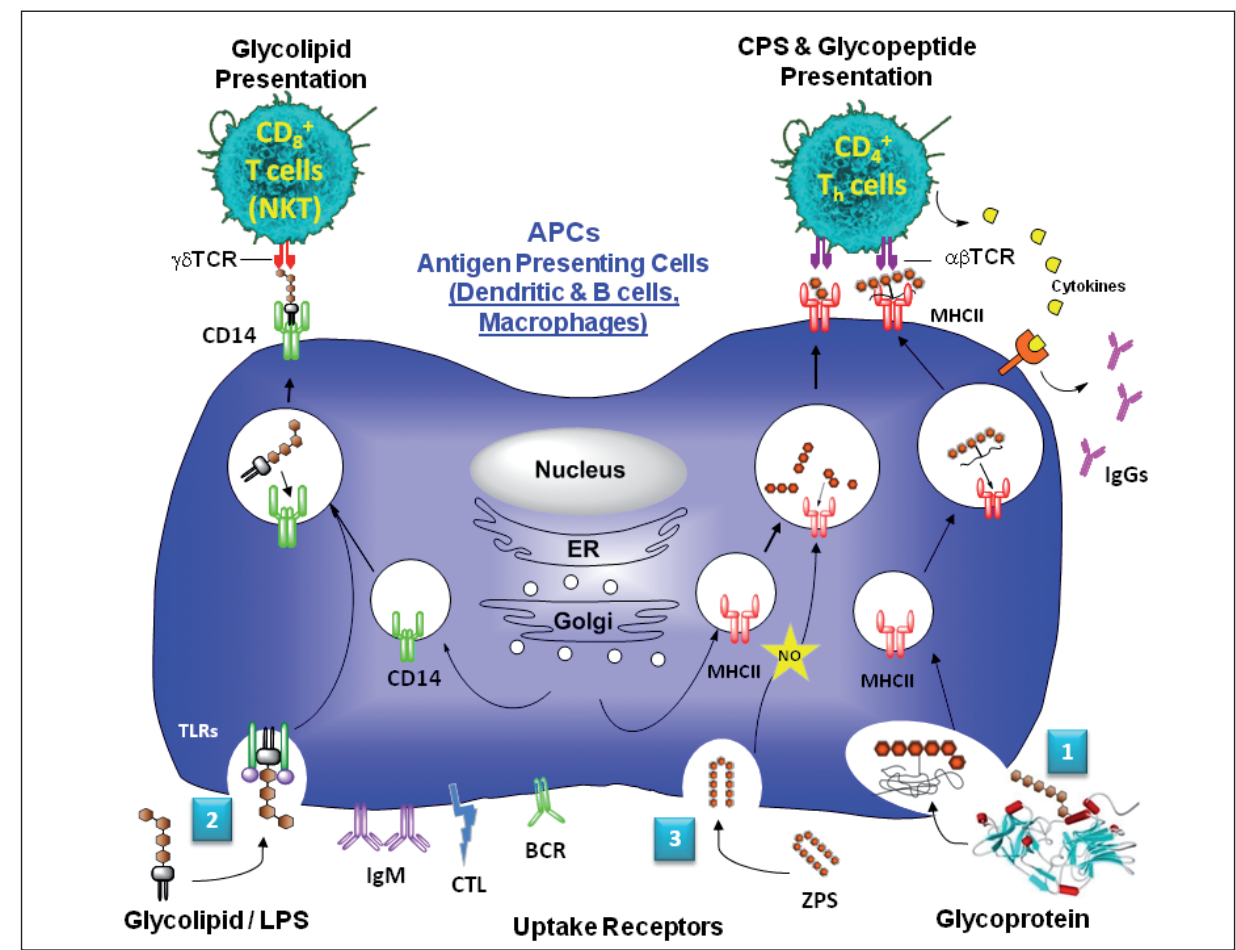

Fig. 1. The three known carbohydrate antigen uptake mechanisms by Antigen Presenting Cells (APCs: dendritic cells, B-cells, and macrophages) of the innate/adaptive immune systems. 1) Neoglycoproteins (conjugated vaccines) are presented to $\alpha \beta$-TCR molecules on CD4+ T-helper cells by $\mathrm{MHC}$ class II proteins in association with co-receptors that triggers signaling pathways leading to $\mathrm{B}$ cell proliferation, differentiation, and ultimately to high affinity lgG-type antibody production and memory. 2) Lipidated antigens are internalize by Toll-like receptors (TLRs) through endosomal pathways and presented to $\gamma \delta$-TCR on T cells by Clusters of Differentiation (CDs). 3) Zwitterionic bacterial polysaccharides (ZPS) conjugated to carbohydrate antigens can also be internalized, processed by nitric oxide (NO)-dependent degradation, and presented to Th-cells in the context of $\mathrm{MHCll}$ receptors. (Adapted from ref. [5]).

PharmaQAM - Department of Chemistry Université du Québec à Montréal

P.O. Box 8888, Succ. Centre-ville, Montreal

Quebec, Canada H3C 3P8

Tel.: +1 5149873000 ext. 2546

Fax: +15149874054

E-mail: roy.rene@uqam.ca 
diphtheria toxoid (DT) (case 1 in Fig. 1) all of which express several key peptide sequences (usually 15-mer long). Of course, initial laboratory models, through which linker development was achieved, consisted of readily available bovine (BSA) or human (HSA) serum albumins.

The second entry mechanism was based on the early observations that Toll-like receptors (TLRs) are capable of internalizing lipid-bound antigens. ${ }^{[10]}$ TLRs are considered as 'pattern recognition' receptors. Common carbohydrate antigens harboring such lipophilic moieties are members of Lipid A, the inner most of the three regions of Gram-negative lipopolysaccharides (LPS), glycolipids, and gangliosides. Known human Toll-like receptors constitute a family of ten protein members recognizing a wide variety of microbial lipophilic molecules. ${ }^{[11]}$ One of which has particularly retained the attention of glycochemists, the TLR2 receptor. ${ }^{[12]}$ TLR2 has been shown to initiate potent immune responses by initially recognizing simple diacylated and triacylated lipopeptides such as Pam ${ }_{3}$ CysSerLys bound $\left(\mathrm{Pam}_{3} \mathrm{CSK}_{4}\right)$ peptides. Therefore, these well-characterized TLR ligands have been utilized in conjugation to specific carbohydrate antigens to create a new family of hybrid glycoconjugates fully equipped with the necessary accessory molecules to trigger the required immune responses.

Finally, a more recent and third entry mechanism was identified wherein zwitterionic polysaccharides (ZPS) could invoke, on their own, MHCII-mediated CD4+ $\mathrm{T}$-cell responses in the absence of protein carriers (Fig. 1). Several bacterial polysaccharides have zwitterionic elements, among these, Bacteroides fragilis PSA1 and PSA2, and Streptococcus pneumoniae Sp1 harbor multiple charges. Hence, recent reports are now emerging describing the covalent attachment of carbohydrate epitopes to such carriers and an example will also be discussed below for a tumor-associated carbohydrate antigen.

\section{Receptor 1: Neoglycoprotein Conjugate}

\subsection{Antibacterial Vaccines}

Several reviews have properly covered the historical developments of bacterial polysaccharide-based vaccines ${ }^{[1-8]}$ and conjugation methods. ${ }^{[13]}$ So this topic will only be briefly presented. It can be safely stated that earlier vaccine preparations composed of diverse bacterial components represented the first successful vaccine generations. Obviously then, given the immature development of bioanalytical chemistry, these vaccine compositions were not without problems and side effects, particularly since trace amounts of DNA and lipolysaccharides

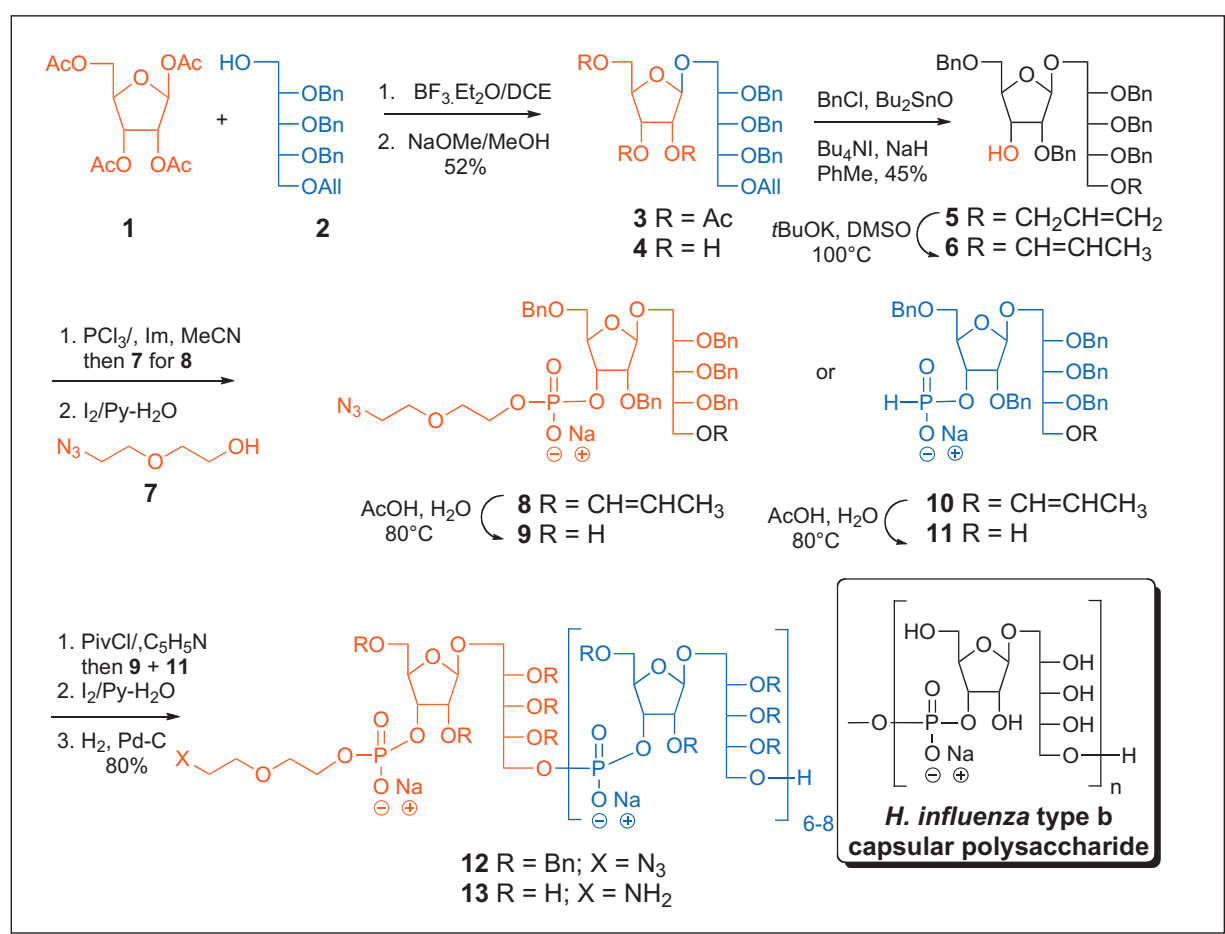

Scheme 1. Chemical sequences leading to a one-step solution-phase synthesis of poly-(ribosylribitol-phosphate) oligomers from the bacterial capsular polysaccharide of the Gram-negative Haemophilus influenza type b using $\mathrm{H}$-phosphonate chemistry.

were present. An important discovery has been revealed by the finding that purified bacterial capsular polysaccharides (CPS) could trigger protective immunity. These are considered second-generation vaccines. Unfortunately, it was quickly realized that the CPS-induced antibodies were of the IgM isotype and thus, were of low affinity and specificity and that they were not long lasting. Moreover, they were inefficient for the populations most at risks, i.e. infants and the elderly whose immune systems are either immature or are losing efficacy, respectively. However, a cornerstone achievement was accomplished through the development of polysaccharide protein conjugate vaccines. ${ }^{[14]}$ Such vaccines of the third generation have essentially permitted eradication of several diseases worldwide. Yet, another major improvement has materialized into a commercial product through synthetic organic chemistry. Indeed, research toward synthetic polysaccharide fragments (oligosaccharides), bearing the minimal carbohydrate epitopes, has been intensively pursued over several years in both academic and industrial laboratories, but success was only accomplished for the first time in 2004 when a Cuban and a Canadian team unified their efforts. ${ }^{[3,15-18]}$ The first carbohydratebased semi-synthetic commercial vaccine was born through chemical synthesis of oligomers of the repeating units of the CPS from Haemophilus influenza type b poly(ribosyl-ribitol-phosphate) which, when properly conjugated to tetanus toxoid used as protein carrier constituted the fourth gen- eration vaccine. ${ }^{[15]}$ Research is now actively going on to provide fully synthetic hybrid molecules which will represent fifth generation vaccines. Progress in that direction will be discussed below through the development of cancer vaccines against tumorassociated carbohydrate antigens overlay expressed on tumor cells. [19-24]

\subsection{Quimi-Hib ${ }^{\circledR}$ - The First Commercial Synthetic Vaccine: Synthesis of Poly-(ribosyl-ribitol- phosphate) Oligomers}

Previous syntheses of poly-(ribosylribitol-phosphate) oligomers suffered from serious drawbacks for commercial application. ${ }^{[16]}$ They were all based on stepwise solid-phase approaches that provided very low overall yields and large-scale synthesis was therefore problematic. The strategy followed by our team was to perform a onestep oligomerization using H-phosphonate chemistry. ${ }^{[25]}$ It was also necessary to shorten the synthetic sequence leading to key ribosyl-ribitol disaccharide 6 (Scheme 1). This was readily achieved by Lewis acidcatalyzed glycosidation of peracetylated D-ribofuranose 1 with ribitol derivative 2 which, after de- $O$-acetylation, provided 3 . Selective benzylation of triol 3 was successfully performed using tin acetal chemistry. Large-scale access to suitably protected disaccharide 6 was one of the key achievements in the new synthesis of the required Hib antigen. ${ }^{[15-17]}$

H-phosphonate precursors 9 and $\mathbf{1 1}$ were prepared in excellent yield and purity 
$\left(\mathrm{PCl}_{3}\right.$, imidazole, $\left.\mathrm{CH}_{3} \mathrm{CN}\right)$ and deprotected at the ribitol's primary hydroxyl group. A fine tuning of the reactivity between the chain terminating component 9 and chain elongating $\mathbf{1 1}$ as well as conditions to avoid competing pivaloylation reaction were shown to be crucial. The synthetic oligomer 12, having an average of eight repeating units, was reproducibly obtained in excellent yield. This yield was several times higher than the overall yields obtained by solid-phase methods. Complete deprotection of benzyl ethers and azide reduction, although challenging, was successfully achieved by hydrogenolysis in the presence of $10 \% \mathrm{Pd} / \mathrm{C}$ in suitable solvent mixture.

The terminal amine functionality was then treated with 3-maleimidopropionic acid N-hydroxysuccinimidate $\mathbf{1 4}$ to provide 15, the key synthetic fragment of Haemophilus influenzae type b ready for conjugation to protein carriers (Scheme 2). This process was simple enough to be reproduced in 100 $\mathrm{g}$ scale batches (10 million vaccine doses). Several proteins from bacterial origin were tested as carrier candidates. Finally, tetanus toxoid (TT) was selected because of its many advantages and relatively low cost. It contains several murine and human T-cell peptide epitopes recognized by $\mathrm{MH}$ CII. Moreover it has long been safely used in humans. A particular sequence, peptide 830-845 has also been utilized systematically in the context of MHCII presentation to CD4+ T-cells. ${ }^{[26]}$ Toward this end, tetanus toxoid was initially thiolated with $\mathrm{N}$ hydroxysuccimide dithioproprionate $\mathbf{1 6}$ to provide $\sim 30$ lysine amino groups modified 17. ${ }^{[18]}$ Maleimido derivative $\mathbf{1 5}$, serving as Michael-type acceptor, was then conjugated to thiolated protein carrier (T-cell epitope) $\mathbf{1 7}$ to give $\mathbf{1 9}$ in $\sim 50 \%$ yield using mild conditions. Finally, compound $\mathbf{1 9}$ was further developed as a vaccine that was registered in Cuba and, as early as January 2004, it was included in the regular vaccination program.

\subsection{Synthetic Peptide Carrier - Natural CPS}

An interesting complementary strategy has been followed through which an immunogenic peptide sequence, acting as a universal T-cell epitope, was used as a carrier for naturally occurring bacterial capsular polysaccharides acting as B-cell epitopes. ${ }^{[27]}$ There are quite a few such universal peptidic T-cell epitopes and bioinformatics can be helpful to identify them. Thus, prototypical carbohydrate-conjugate vaccines composed of a non-natural 13 amino acid universal pan HLA-DR derived MHCII presenting molecule (PADRE) and Streptococcus pneumoniae capsular polysaccharides from serotypes $6 \mathrm{~B}, 9 \mathrm{~V}$, and 14 have been prepared. ${ }^{[27]}$ Several constructs composed of 1:1 molar ratios of the PADRE peptide

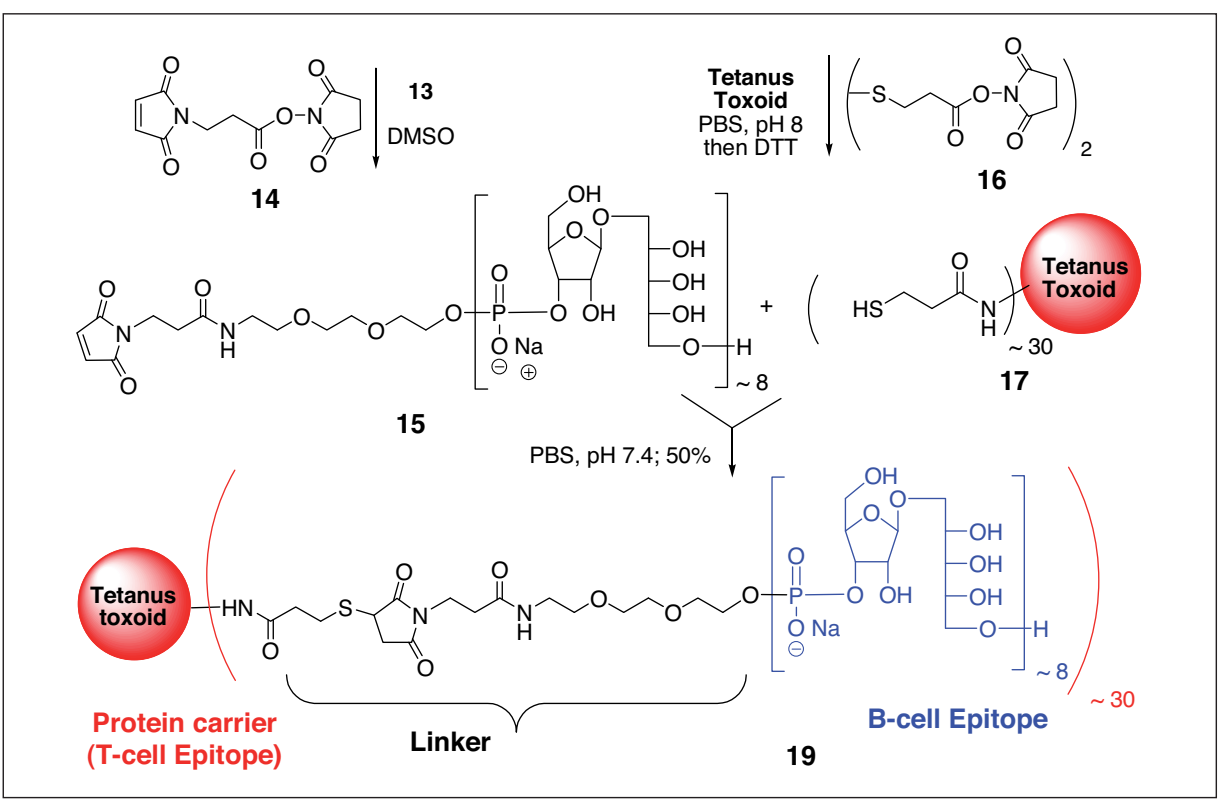

Scheme 2. Chemical ligation of the maleimido derivative of $H$. Influenza type b oligomers 15 with thiolated tetanus toxoid carrier 17 providing the first commercial example of a semi-synthetic carbohydrate-based vaccine. ${ }^{[15]}$

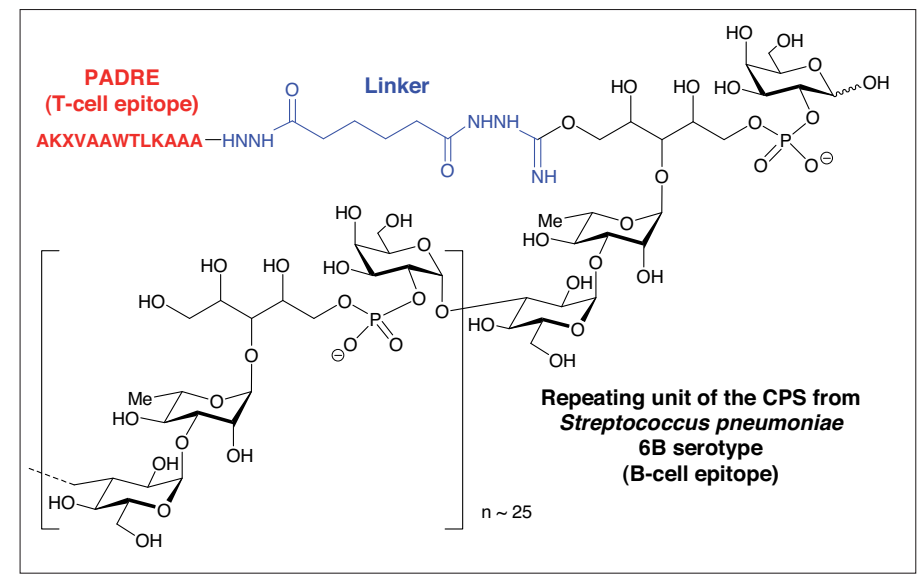

Fig. 2. Streptococcus pneumoniae serotype $6 \mathrm{~B}$ conjugated to the universal helper T-lymphocyte epitope (PADRE $^{\circledR}$ ) using cyanogen bromide activation of the polysaccharide, reaction with adipic acid dihydrazide, followed by coupling to the peptide with a carbodiimide (EDC). ${ }^{[27]}$ and the CPS were successfully used to raise murine antibodies that were shown to be opsonic and which could mediate phagocytosis of pneumococci. The conjugates were simply prepared using carbodiimide coupling (Fig. 2).

Additional examples, including fully synthetic oligosaccharides, were provided against dodecasaccharide from Salmonella typhimurium O-antigen, ${ }^{[28]}$ Shigella flexneri serotype $2 \mathrm{a},{ }^{[29-31]}$ and even a tumor marker, the Tn antigen ( $\alpha$-D-GalNAc, see below). [32] Interestingly, the mice $\operatorname{IgG}$ antibody titers produced from the $S$. typhimurium vaccine were comparable to the one produced when human serum albumin (HSA) was used as carrier protein. Moreover, modulation of antibody isotype profiles were obtained with different adjuvant: alum $\left(\mathrm{KAl}\left(\mathrm{SO}_{4}\right)_{2} \cdot 12 \mathrm{H}_{2} \mathrm{O}\right)$ supported $\mathrm{IgG} 1$; QS-21 provided IgG2a, $2 \mathrm{~b}$ profile, while a combination of alum and QS-21 generated IgG1/ $\mathrm{IgG} 2 \mathrm{~b}$ isotype profile. Of note is the popular adjuvant QS-21 now in clinical phase III for varied vaccine compositions. ${ }^{[33]} \mathrm{QS}-21$ is a saponin adjuvant isolated from the bark of the Quillaja saponaria Molina tree. It is a water-soluble triterpene glycoside with amphiphilic character that can be mixed with soluble antigens resulting in fully soluble vaccine formulation. Its synthesis has been previously described. ${ }^{[34]}$

\subsection{Cancer Vaccines}

Malignant cells over express a glycoprotein known as MUC1 mucin. ${ }^{[35]}$ This glycoprotein is heavily glycosylated in normal cells while limited $O$-glycosylation on cancer cells has been clearly demonstrated. Gangliosides (GM2, GD2, GD3) and neutral glycolipids (globo-H and Lewis ${ }^{y}$ ) on epithelial tumor cells of breast, lung, colon, bladder, and prostate are also considerably altered both in number and in structures. ${ }^{[1,2,19-24]}$ In the tumor-associated carbohydrate antigens (TACAs) of mucins, a down-regulation of $\beta-1,6-$ GlcNAc transferase, provokes an accumulation of shorter glycan chain 


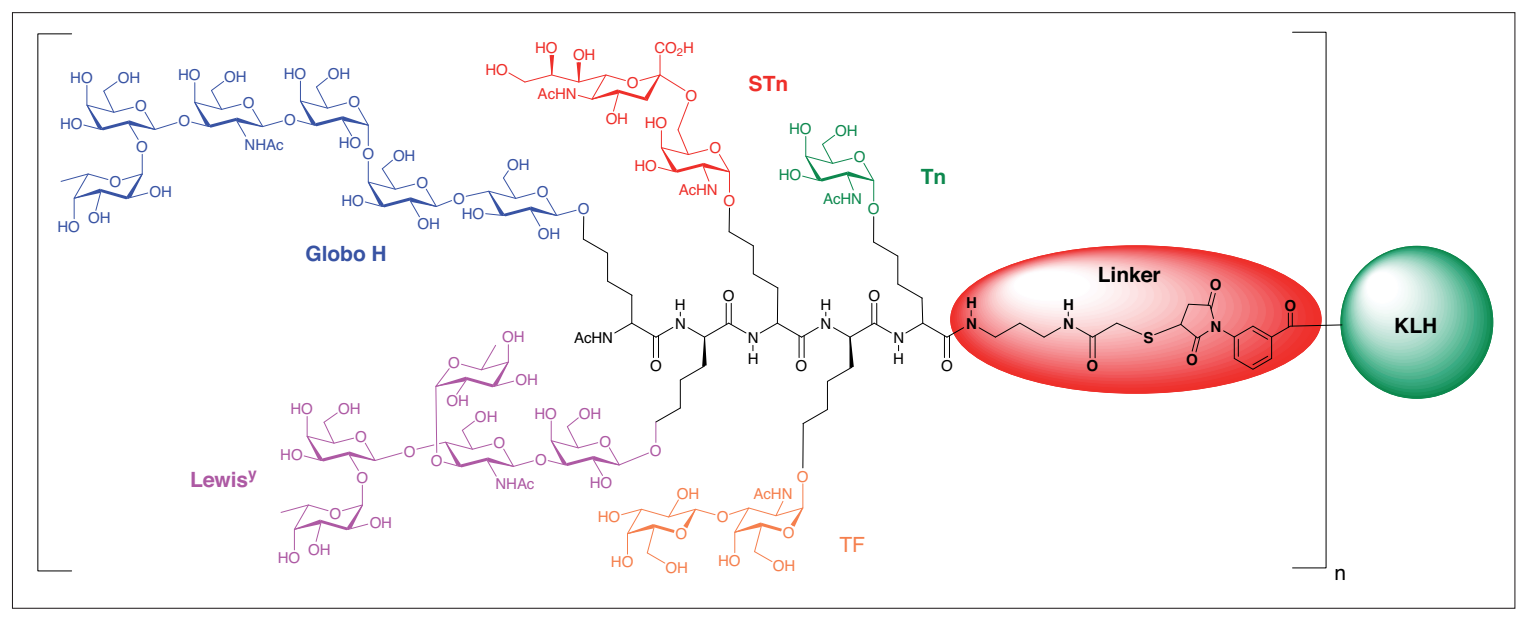

Fig 3. Semi-synthetic tumor vaccines harboring multivalent TACAs linked to keyhole limpet hemocyanin $(\mathrm{KLH}) \cdot{ }^{[20,38]}$

$\beta$-Gal-( $1 \rightarrow 3)$ - $\alpha$-GalNAc- $O$-Ser/Thr $\quad$ (referred to as the T- and the TF-antigen (TF $=$ Thomsen-Friedenreich)). In healthy tissues, the active enzyme is responsible for a much more complex pattern of glycation, amounting to $50 \%$ of the glycoprotein masses. The consequences of these modified glycosylation profiles are profound as they contribute to MUC1, and to a lesser extent MUC4, conformational changes, better exposition of peptide backbones, and obviously to an over accumulation of the above carbohydrate-based cancer markers which are otherwise cryptic (masked) on healthy tissues. Furthermore, large amounts of the $\alpha$-GalNAc- $O$-Ser/Thr (Tn-antigen) precursor are also accumulated together with the corresponding sialylated counterparts (sialyl T- or sialyl-Tn antigens (ST and STn)) due to an 8-10 fold increase activity of sialyltransferases in tumor cells. Consequently, most efforts to provide classical carbohydrate-based vaccines have been devoted, albeit with limited success, to the above antigens. However, patients with higher levels of anti-tumor associated carbohydrate antigens antibodies have a better prognosis than patients with lower levels.

In spite of the limited success encountered with traditional vaccine formulations based on neoglycoproteins harboring the above carbohydrate antigens, ${ }^{[36,37]}$ considerable efforts have been invested in the chemical design of novel architectures. Thus, Danishesfky and co-workers from the Sloan-Kettering Institute for Cancer Research (NY, USA) have developed systematic research projects aimed at the synthesis of various vaccine compositions. ${ }^{[19,20]}$ One of the approaches is particularly appealing in that they synthesized a rather complex multi-epitopic B-cell conjugate bearing the five most common TACAs (Fig. 3). The potential commercial limitation of this approach is however foreseeable as the chemical analysis of the resulting neoglycoprotein is rather complex given that KLH is an extremely large heterogeneous glycoprotein composed of several $350 \mathrm{kDa}$ subunits affording a material of molecular weight ranging from 4.5-13M Da. Indeed, an analogous vaccine made of the single sialyl-Tn TACA, initially developed by Biomira Inc. in Alberta (Canada) (Theratope ${ }^{\circledR}$ ) and then by Merck, was abandoned in clinical Phase III. ${ }^{[39]}$ Alternatively, an equivalent liposomal preparation (Stimuvax ${ }^{\circledR}$, Merck Serono) has recently resumed clinical Phase III investigations in June 2010.

Kunz and coworkers have further advanced the field of TACA-based immunochemistry by synthesizing multiple vaccine variations $^{[24,40]}$ (see article by Westerlind and Kunz in this issue). They concluded that, even when conjugated to BSA, mostly IgM murine isotypes were triggered. ${ }^{[41]} \mathrm{Ad}-$ ditionally, fully synthetic conjugates consisting of TACAs' glycopeptides linked to T-cell epitopes from ovalbumin could raise selective IgGs in only a third of transgenic mice. ${ }^{[42,43]}$ Moreover, they showed that STn-MUC1 peptide-tetanus toxoid conjugate elicited strong immune responses, ${ }^{[44]}$ while the corresponding and fully synthetic construct bearing a TLR-2 lipopeptide ligand $\left(\mathrm{Pam}_{3} \mathrm{CSK}_{4}\right)$ could also behave likewise. ${ }^{[45,46]}$ Similarly, Boons et al. also reported the efficacy of a fully synthetic vaccine harboring the MUC1-Tn antigen built on a TLR-2 Pam $_{3} \mathrm{CSK}_{4}$ lipopeptide (see below). ${ }^{[47]}$

Additional examples can be found in the literature concerning strategies leading to TACAs-based vaccine candidates. ${ }^{[19-24]}$ It was also found that the resulting antibodies may be useful as antimetastatic agents. ${ }^{[48]}$ One interesting case has been reported in which the TF-antigen has been replaced by peptides (Fig. 4), ${ }^{[49]}$ a situation also elegantly explored by the group of Pinto et al. who demonstrated that oligosaccharides of the repeating units of the CPS from Group A and B Streptococcus and Shigella flexneri Y could be replaced by peptide-mimics. ${ }^{[50]}$

In a recent work, Roy et al. successfully tested the hypothesis that vaccinations with unique TF-Ag peptide mimics may generate immune responses to $\mathrm{TF}-\mathrm{Ag}$ epitopes on tumor cells, useful for active immunotherapy against relevant cancers. ${ }^{[49]}$ Peptide mimics of TF-Ag were selected by phage display biopanning using previously generated JAA-F11 mouse monoclonal antibody and rabbit anti-TF-Ag Ab and were analyzed in vitro to confirm TF-Ag peptide mimicry. In vitro, TF-Ag peptide mimics bound to TF-Ag-specific peanut agglutinin and blocked TF-Ag-mediated rolling and stable adhesion of cancer cells to vascular endothelium. In vivo, the immunization with TF-Ag-mimicking multiple antigenic peptides induced TF-Ag-reactive Ab production. The vaccine represented a commendable example of dendritic architecture (Fig. 4).

\section{Receptor 2: Glycolipid Conjugates}

As mentioned in the introduction, lipidbound antigens can be directly recognized by Toll-like receptors (TLRs) (Fig. 1) and the Lipid A portion of Gram-negative bacteria has been co-crystallized with TLR4, ${ }^{[11]}$ while TLR 2 was cocrystallized with $\mathrm{Pam}_{2} \mathrm{C}$ $\mathrm{SK}_{4}$ (Fig. 5). ${ }^{[12]}$ The overall consequences of this and similar observations was that glycochemists initiated intensive research programs aimed at grafting carbohydrate antigens onto lipopeptides..$^{[1,2]} \mathrm{A}$ powerful example of this situation has been described for the TACAs' antigens described above ${ }^{[45,46]}$ and bacterial CPS. ${ }^{[51]}$

A fully synthetic three-component vaccine synthesized from a TLR2 $\mathrm{Pam}_{3} \mathrm{CSK}_{4}$ lipopeptide ligand, a promiscuous T-helper epitope identified from a well-documented mouse major histocompatibility complex (MHCII) from the polio virus $\left(\mathrm{PV}_{103-115}\right)$ and a tumor-associated glycopeptide Tn-MUC1 can elicit remarkably high antibody titers of $\mathrm{IgG}$ isotype in mice. The antibodies were shown to recognize cancer cells expressing the tumor-associated carbohydrate. The superior properties of the vaccine candidate were attributed to the local production of 


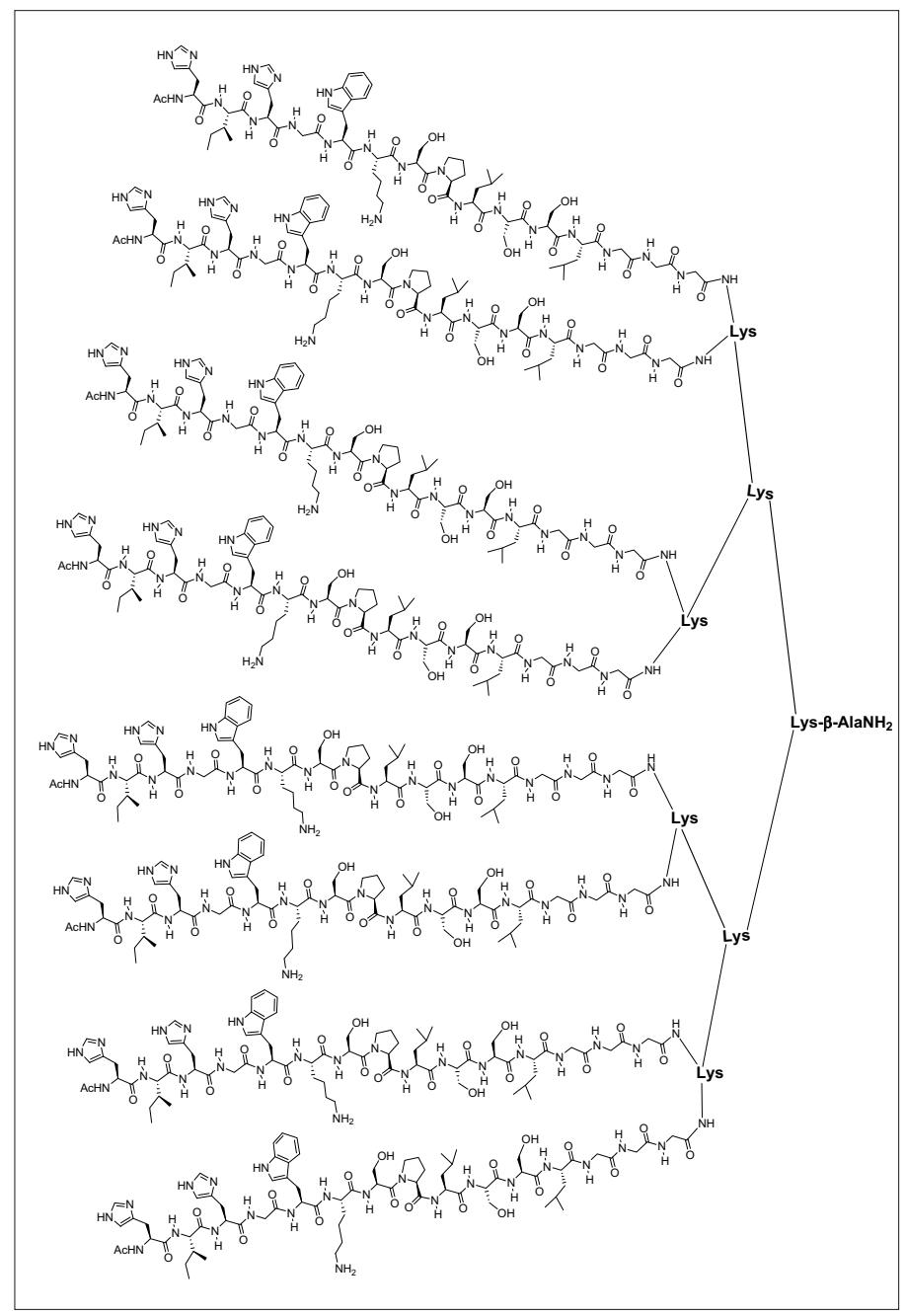

Fig. 4. Antigenic carbohydrate epitopes can be functionally replaced by peptide sequences. When multimerized into a dendritic molecular architecture, the resulting neoglycoconjugates can not only be recognized by anti-carbohydrate antibodies but can also act to trigger an successful immune response. ${ }^{[49]}$

cytokines, upregulation of costimulatory proteins, enhanced uptake by macrophages and dendritic cells and avoidance of epitope suppression. ${ }^{[46]}$

\section{Receptor 3: Zwitterionic Polysaccharides}

Following the seminal observations by the Kasper group ${ }^{[5,52]}$ indicating that zwitterionic polysaccharides (ZPS) from various bacterial species could be endocytized, internalized, processed into smaller pieces through nitric oxide degradation by typical APCs and presented within the MHCII to CD4+ Th-cells (Fig. 1), activities were initiated to capitalize on the findings to generate TACAs-based vaccines. As stated above, bacterial polysaccharides from Bacteroides fragilis PSA1 and PSA2, and Streptococcus pneumoniae Sp1 are representative examples of ZPS. The group of Andreana has thus generated a Tn-PS A1 vaccine. ${ }^{53]}$

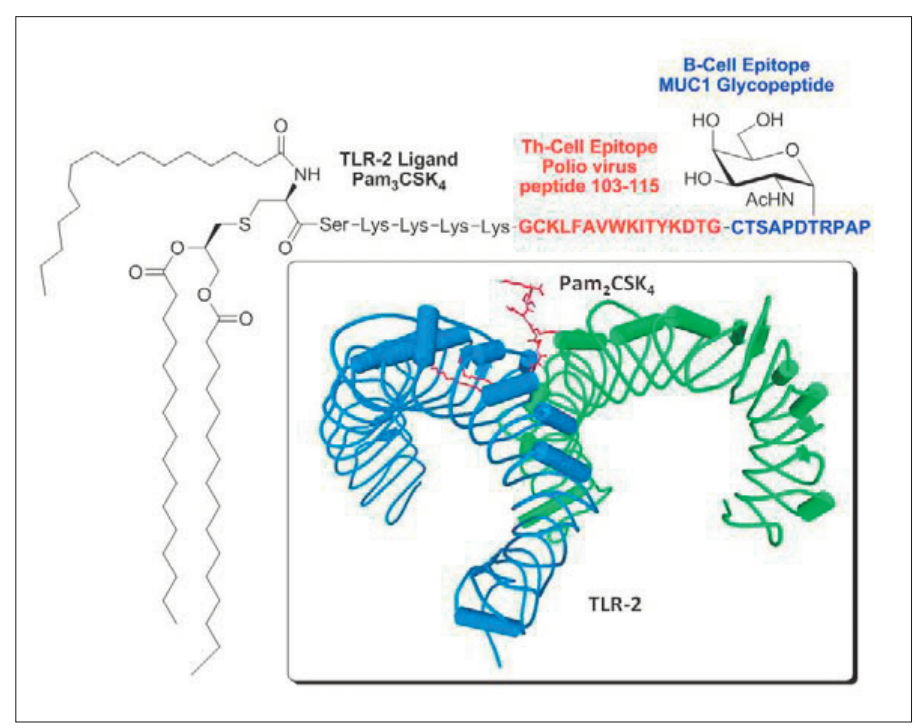

Fig. 5. Inset: TLR2 cocrystallized with the lipopeptide $\mathrm{Pam}_{2} \mathrm{CSK}_{4}$ (PDB No. 3A79); chemical structure of a fully synthetic carbohydrate-based anticancer vaccine.

Importantly, this finding further illustrates that the oxime linkage did not undergo sufficiently rapid hydrolysis to prevent immune response in vivo. This vaccine prototype represents a commendable example of a fully carbohydrate-based T-cell dependent immunogen.

\section{Other Vaccines and Conclusion}

Obviously, several other human pathologies are being investigated through prophylactic vaccine treatments and glycobiologists have accordingly concentrated their efforts in that direction. Given our deeper understanding of antigen uptake mechanisms, the creativity of organic chemists has greatly contributed to the versatility of vaccine design. Additionally, the sophistication of modern analytic tools to better identify naturally occurring carbohydrate antigens including crystallography, our improve capacity to screen ligands and receptors through microarrays, and the many novel strategies to synthesize complex oligosaccharides and create glycomimetics thereof, have greatly improved our capacity to undertake immunochemistry. Due to space limitation, this brief review could not cover several other beautiful synthetic applications and we apologize to researchers actively involved in the field whose work have not been covered herein. For several other disease applications, the readers are strongly encourage to consult the following readings: anti-HIV vaccines based on multiantennary mannosides $\left(\mathrm{Man}_{9} \mathrm{GlcNAc}_{2}\right)$ present on gp120,[54-61] the excellent contributions on rheumatoid arthritis, ${ }^{[62]}$ antifungal, ${ }^{[63-65]}$ as well antiparasitic ${ }^{[66,67]}$ and clamydial[68] infections.

Received: October 29, 2010 


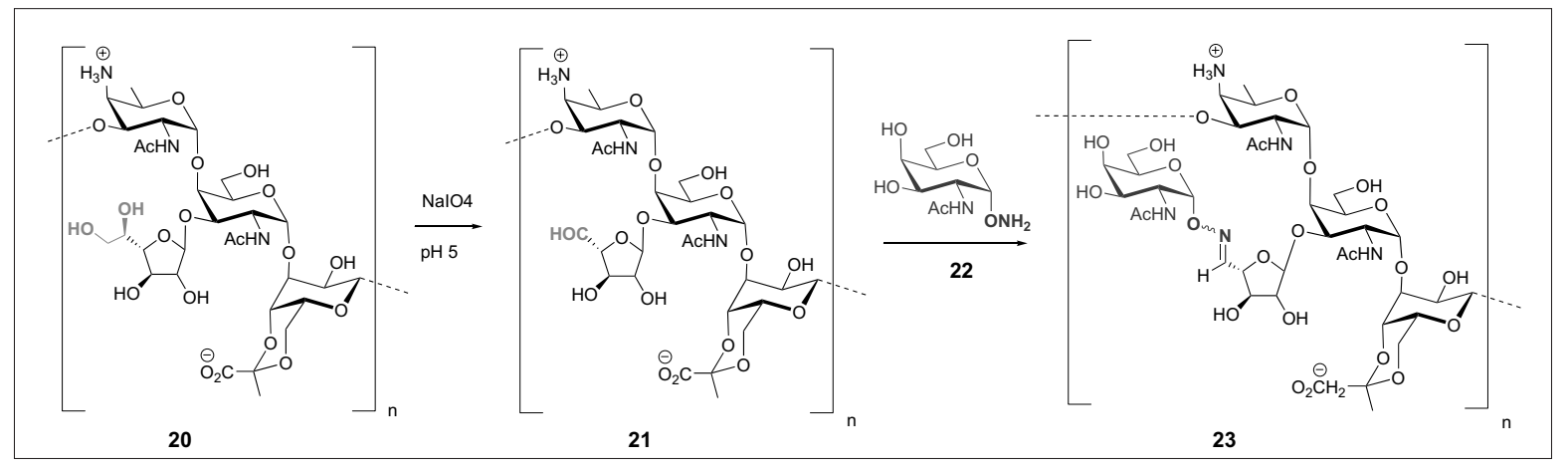

Scheme 3.

Zwitterionic bacterial polysaccharide from Bacteroides fragilis used as MHCIl carrier for a Tn-antigen elicited T-cell dependant immune response and provided high titer IgG3 antibody isotype.

[1] 'Carbohydrate-based Vaccines', Ed. R. Roy, ACS Symp. Ser. 2008, 989.

[2] 'Carbohydrate-Based Vaccines and Immunotherapies', Eds. Z. Guo, G. J. Boons, John Wiley \& Sons, Hoboken, New Jersey, 2009

[3] R. Roy, Drug Discov. Today:Technologies 2004, $1,327$.

[4] V. Fernández Santana, Y. Valdés Balbin, J. Chang Calderón, L. Peña Icart, V. Verez Bencomo, in 'Glycoscience', Eds. B. Fraser-Reid, K. Tatsuta, J. Thiem, Springer-Verlag, Berlin, 2008, Chap. 12.9, 2700.

[5] B. A. Cobb, D. L. Kasper, Eur. J. Immunol. 2005, 35,352 .

[6] H. Snippe, W. T. M. Jansen, J. P. Kamerling, in 'Carbohydrate-based Vaccines', Ed. R. Roy, ACS Symp. Ser. 2008, 989, 85 .

[7] V. Pozsgay, Adv. Carbohydr. Chem. Biochem. 2000, 56, 153.

[8] V. Pozsgay, Curr. Top. Med. Chem. 2008, 8, 126.

[9] L. Peña Icart, V. Fernandez Santana, R. C. Veloso, T. Carmenate, S. Sirois, R. Roy, V. Verez Bencomo, ACS Symp. Ser. 2008, 989, 1.

[10] R. Spohn, U. Buwitt-Beckmann, R. Brock, G. Jung, A. J. Ulmer, K.-H. Wiesmüller, Vaccine 2004, 22, 2494.

[11] B. S. Park, D. H. Song, H. M. Kim, B.-S. Choi, H. Lee, J.-O. Lee, Nature 2009, 458, 1191.

[12] J. Y. Kang, X. Nan, M. S. Jin, S.-J. Youn, Y. H. Ryu, S. Mah, S. H. Han, H. Lee, S.-G. Paik, J.-O. Lee, 2009, 31, 873

[13] V. Pozsgay, J. Kubler-Kielb, in 'Carbohydratebased Vaccines', Ed. R. Roy, ACS Symp. Ser. 2008, 989,36

[14] K. Landsteiner, H. Lampl, Biochem. Zeitschr. $1918,86,343$.

[15] V. Verez-Bencomo, V. Fernández-Santana, E. Hardy, M. E. Toledo, M. C. Rodriguez, L. Heynngnezz, A. Rodriguez, A. Baly, L. Herrera, M. Izquierdo, A. Villar, Y. Valdés, K. Cosme, M. L. Deler, M. Montane, E. Garcia, A. Ramos, A. Aguilar, E. Medina, G. Toraño, I. Sosa, I. Hernandez, R. Martínez, A. Muzachio, A Carmenates, L. Costa, F. Cardoso, C. Campa, M Diaz, R. Roy, Science 2004, 305, 522.

[16] V. V. Bencomo, R. Roy, M. C. Rodriguez, A. Villar, V. Fernandez-Santana, E. Garcia, Y. Valdes, L. Heynngnezz, I. Sosa, E. Medina, ACS Symp. Ser. 2008, 989, 71.

[17] V. Verez-Bencomo, R. Roy, WO Patent 01/16146, 2001; U.S. Patent 6,765,091, 2004.

[18] V. Fernández-Santana, F. Cardoso, A. Rodriguez, T. Carmenate, L. Peña, Y. Valdés, E. Hardy, F. Mawas, L. Heynngnezz, M. C. Rodríguez, I Figueroa, J. Chang, M. E. Toledo, A. Musacchio, I. Hernández, M. Izquierdo, K. Cosme, R. Roy, V. Verez-Bencomo, Infect. Immun. 2004, 72, 7115.

[19] S. J. Danishefsky, J. R. Allen, Angew. Chem. Int Ed. 2000, 39, 836 .

[20] R. M. Wilson, J. David Warren, O. Ouerfelli, S. J. Danishesky, in 'Carbohydrate-based Vaccines', Ed. R. Roy, ACS Symp. Ser. 2008, 989, 258.

[21] D. R. Bundle, Nat. Chem. Biol. 2007, 3, 605.

[22] T. Buskas, P. Thompson, G.-J. Boons, Chem. Commun. 2009, 5335 .
[23] Z. Guo, Q. Wang, Curr. Opin. Chem. Biol. 2009, 13,608 .

[24] U. Westerlind, H. Kunz, Carbohydr. Chem. 2010, $36,1$.

[25] A. V. Nikolaev, J. A. Chudek, M. A. J. Fergusson, Carbohydr. Res. 1995, 272, 179.

[26] F. Falugi, R. Petracca, M. Mariani, E. Luzzi, S. Mancianti, V. Carinci, M. L. Melli, O. Finco, A. Wack, A. Di Tommaso, M. T. De Magistris, P. Costantino, G. Del Giudice, S. Abrignani, R. Rappuoli, G. Grandi, Eur. J. Immunol. 2001, 31, 3816.

[27] J. Alexander, M.-F. del Guercio, B. Frame, A. Maewal, A. Sette, M. H. Nahm, M. J. Newman, Vaccine 2004, 22, 2362.

[28] J. Alexander, M.-F. del Guercio, A. Maewal, L. Qiao, J. Fikes, R. W. Chesnut, J. Paulson, D. R. Bundle, S. DeFrees, A. Sette, J. Immunol. 2000, 164, 1625.

[29] F. Bélot, C. Guerreiro, F. Baleux, L. A. Mulard, Chem. Eur. J. 2005, 11, 1625.

[30] L. A. Mulard, A. Phalipon, in 'Carbohydratebased Vaccines', Ed. R. Roy, ACS Symp. Ser. 2008, 989, 105.

[31] K. Wright, C. Guerreiro, I. Laurent, F. Baleux, L. A. Mulard, Org. Biomol. Chem. 2004, 2, 1518.

[32] S. Vichier-Guerre, R. Lo-Man, L. BenMohamed, E. Dériaud, S. Kovats, C. Leclerc, S. Bay, J. Pept. Res. 2003, 62, 117.

[33] S. K. Kim, G. Ragupathi, C. Musselli, S. J. Choi, Y. S. Park, P. O. Livingston, Vaccine 1999, 18, 597.

[34] K. Deng, M. M. Adams, P. Damani, P. O. Livingston, G. Ragupathi, D. Y. Gin, Angew. Chem. Int. Ed. 2008, 47, 6395.

[35] G. F. Springer, Science 1984, 224, 1198.

[36] K. Rittenhouse-Diakun, K. Xia, D. Pickhardt, M.G. Baek, R. Roy, Hybridoma 1998, 17, 165.

[37] R. Roy, M.-G. Baek, K. Rittenhouse-Olson, $J$. Am. Chem. Soc. 2001, 123, 1809

[38] G. Ragupathi, F. Koide, P. O. Livingston, Y. S. Cho, A. Endo, Q. Wan, M. K. Spassova, S. J. Keding, O. Ouerfelli, S. J. Danishesky, J. Am. Chem. Soc. 2006, 128, 2715.

[39] R. R. Koganty, D. Yalamati, Z.-H. Jiang, in 'Carbohydrate-based Vaccines', Ed. R. Roy, ACS Symp. Ser. 2008, 989, 311.

[40] H. Kunz, S. Dziadek, S. Wittrock, T. Becker, in 'Carbohydrate-based Vaccines', Ed. R. Roy, ACS Symp. Ser. 2008, 989, 293.

[41] H. Kunz, S. Birnbach, Angew. Chem. Int. Ed. 1986, 25,360

[42] S. Dziadek, A. Hobel, E. Schmitt, H. Kunz, Angew. Chem. Int. Ed. 2005, 44, 7630.

[43] U. Westerlind, A. Hobel, N. Gaidzik, E. Schmitt, H. Kunz, Angew. Chem. Int. Ed. 2008, 47, 7551.

[44] A. Kaiser, N. Gaidzik, U. Westerlind, D. Kowalczyk, A. Hobel, E. Schmitt, H. Kunz, Angew. Chem. Int. Ed. 2009, 48, 7551.

[45] A. Kaiser, N. Gaidzik, T. Becker, C. Menge, K. Groh, H. Cai, Y.-M. Li, B. Gerlitzki, E. Schmitt, H. Kunz, Angew. Chem. Int. Ed. 2010, 49, 3688.

[46] A. Hoffmann-Röder, A. Kaiser, S. Wagner, N. Gaidzik, D. Kowalczyk, U. Westerlind, B. Gerlitzki, E. Schmitt, H. Kunz, Angew. Chem. Int Ed. 2010, 49, 8498.
[47] T. Buskas, S. Ingale, G.-J. Boons, Angew. Chem Int. Ed. 2005, 44, 5985 .

[48] J. Heimburg, J. Yan, S. Morey, O. V. Glinskii, V. H. Huxley, L. Wild, R. Klick, R. Roy, V. V. Glinsky, K. Rittenhouse-Olson, Neoplasia 2006, 8, 939 .

[49] J. Heimburg-Molinaro, A. Almogren, S. Morey, O. V. Glinskii, R. Roy, G. E. Wilding, R. P. Cheng, V. V. Glinsky, K. Rittenhouse-Olson, Neoplasia 2009, 11,780 .

[50] S. Borrelli, M. A. Johnson, R. B. Hossany, B. M Pinto, in 'Carbohydrate-based Vaccines', Ed. R. Roy, ACS Symp. Ser. 2008, 989, 335.

[51] F. S. Hassane, A. Phalipon, M. Tanguy, C. Guerreiro, F. Bélot, B. Frisch, L. A. Mulard, F. Schuber, Vaccine 2009, 27, 5419.

[52] F. Y. Avci, D. L. Kasper, Annu. Rev. Immunol. 2010, 28, 107

[53] R. A. De Silva, Q. Wang, T. Chidley, D. K. Appulage, P. R. Andreana, J. Am. Chem. Soc. 2009, 131, 9622.

[54] S.-K. Wang, P.-H. Liang, R. D. Astronomo, T. L. Hsu, S.-L. Hsieh, D. R. Burton, C.-H. Wong, Proc. Nat. Acad. Sci. 2008, 105, 3690.

[55] I. J. Krauss, J. G. Joyce, A. C. Finnefrock, H. C. Song, V. Y. Dudkin, X. Geng, J. D. Warren, M. Chastain, J. W. Shiver, S. J. Danishefsky, J. Am. Chem. Soc. 2007, 129, 11042

[56] V. Y. Dudkin, M. Orlova, X. Geng, M. Mandal, W. C. Olson, S. J. Danishefsky, J. Am. Chem. Soc. 2004, 126, 9560 .

[57] X. Geng, V. Y. Dudkin, M. Mandal, S. J. Danishefsky, Angew. Chem. Int. Ed. 2004, 43, 2562.

[58] H. Li, L.-X. Wang, Org. Biomol. Chem. 2004, 2 , 483.

[59] L.-X. Wang, J. Ni, S. Singh, H. Li, Chem. Biol. 2004, 11, 127.

[60] J. Ni, H. Song, Y. Wang, N. M. Stamatos, L.-X. Wang, Bioconjugate Chem. 2006, 17, 493.

[61] J. Wang, H. Li, G. Zou, L.-X. Wang, Org. Biomol. Chem. 2007, 5, 1529.

[62] M. Mogemark, T. P. Cirrito, P. Sjölin, E. R. Unanue, J. Kihlberg, Org. Biomol. Chem. 2003, $1,2063$.

[63] S. Dziadek, S. Jacques, D. R. Bundle, Chem. Eur. J. 2008, 14, 5908

[64] P. I. Kitov, G. L. Mulvey, T. P. Griener, T. Lipinski, D. Solomon, E. Paszkiewicz, J. M. Jacobson, J. M. Sadowska, M. Suzuki, K.-i. Yamamura, G. D. Armstrong, D. R. Bundle, Proc. Nat. Acad. Sci. 2008, $105,16837$.

[65] D. R. Bundle, M. Nitz, X. Wu, J. M. Dadowska, in 'Carbohydrate-based Vaccines', Ed. R. Roy, ACS Symp. Ser. 2008, 989, 163

[66] B. L. Stocker, A. Hölemann, P. H. Seeberger, in 'Carbohydrate-based Vaccines', Ed. R. Roy, ACS Symp. Ser. 2008, 989, 137.

[67] F. Kamena, M. Tamborrini, X. Liu, Y.-U. Kwon, F. Thompson, G. Pluschke, P. H. Seeberger, Nat. Chem. Biol. 2008, 4, 238.

[68] P. Kosma, H. Brade, S. V. Evans, in 'Carbohydratebased Vaccines', Ed. R. Roy, ACS Symp. Ser. 2008, 989, 239 